\title{
Effectiveness of Nootropics in Combination with Cholinesterase Inhibitors on Cognitive Function in Mild-to-Moderate Dementia: A Study Using Real- world Data
}

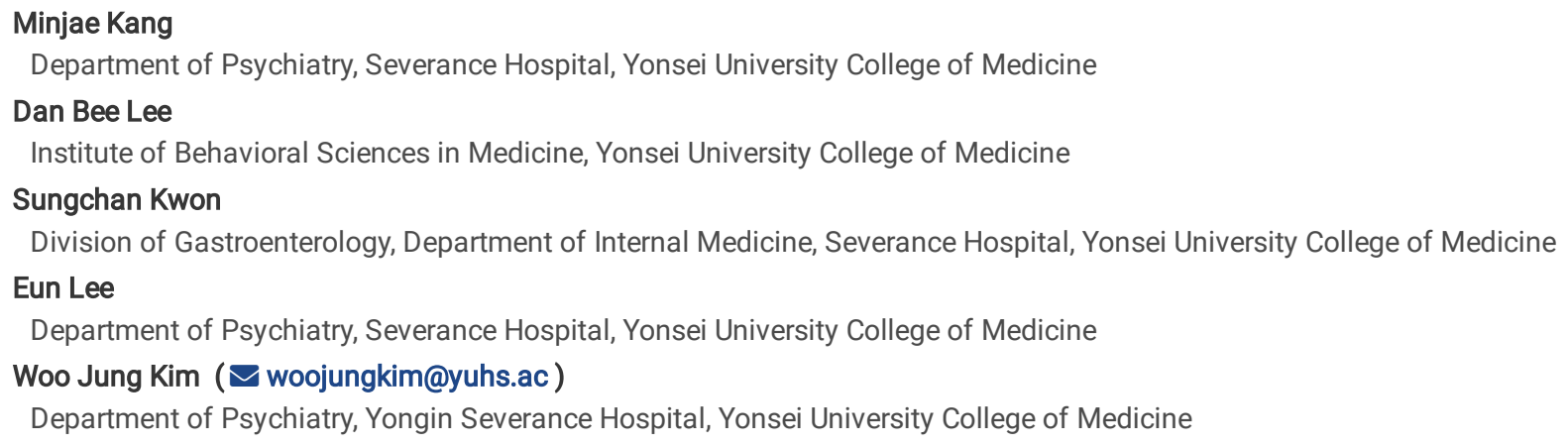

\section{Research Article}

Keywords: Cholinesterase inhibitors, Nootropic agents, Dementia, Alzheimer disease, Cognitive dysfunction, Mental status and dementia test

Posted Date: March 22nd, 2022

DOI: https://doi.org/10.21203/rs.3.rs-1317818/v2

License: () (1) This work is licensed under a Creative Commons Attribution 4.0 International License. Read Full License 


\section{Abstract}

\section{Background}

The clinical benefits of nootropics in the treatment of cognitive decline has been either limited or controversial. This study aimed to observe the effectiveness of cholinesterase inhibitor (ChEl) and nootropics combination in the treatment of cognitive impairment in dementia.

\section{Methods}

Data were based on electronic medical records in a university health system. Patients with mild-to-moderate dementia and no history of prior cognitive enhancer use were included $(n=583)$. The subjects were categorized into the ChEl only group and the ChEl and nootropics combination group. The primary outcome measure was the change in cognitive function, as assessed by the mini-mental state examination (MMSE) from baseline to $300-400$ days after the first ChEl prescription. Subsequent analyses were conducted in consideration of the dementia type, medical adherence, and type of nootropics.

\section{Results}

The changes in MMSE scores from baseline to endpoint were not significantly different between the two groups. In Alzheimer's dementia, the combination group showed significantly less deterioration in MMSE language subscale scores compared to the $\mathrm{ChEl}$ only group $(F=6.86, p=0.009)$, and the difference was consistent in the highly adherent subjects $(F=10.16, p=0.002)$. The choline alfoscerate and the ginkgo biloba extract subgroups in Alzheimer's dementia showed more significant improvements in the MMSE language subscale scores compared to the other nootropics $\operatorname{subgroup}(\mathrm{F}=7.04, \mathrm{p}=0.001)$.

\section{Conclusions}

The present study showed that the effectiveness of $\mathrm{ChEl}$ and nootropics combination on cognition may appear differently according to the dementia type. It emphasizes the need for well-controlled studies to generalize the effectiveness of nootropics across various clinical settings.

\section{Background}

Dementia is one of the most rapidly growing syndromes in aging societies, and it is also the leading cause of disability and caregiver dependency among older adults. Currently, more than 55 million people worldwide are affected by dementia, and nearly 10 million new patients are diagnosed with dementia every year [1]. Dementia leads to deterioration in multiple domains of cognitive function, including orientation, memory, language, attention, and visuospatial construction. To date, no curative drugs for dementia have been widely implemented in clinical practice, and most clinicians still consider cholinesterase inhibitors (ChEls) as the first line of pharmacological treatment for cognitive deficits in dementia [2,3].

Nootropics, which were originally described as compounds with similar pharmacology to piracetam, are now generally accepted as any and all compounds that are expected to improve learning and memory in experimental and clinical paradigms [4]. In Korea, apart from the general over-thecounter supplements, there are certain nootropics that need prescriptions for use; among those most frequently prescribed are choline alfoscerate, ginkgo biloba extract, acetyl-L-carnitine, nicergoline, and oxiracetam. Many clinicians often prefer concomitant use of ChEls with nootropics, based on fragmentary evidence that augmentation could have certain clinical benefits [5, 6]. In fact, the clinical benefits of nootropics in the treatment of cognitive decline are either limited or controversial, with some studies showing improvements in cognitive function with choline alfoscerate [7-9], ginkgo biloba extract [10,11], acetyl-L-carnitine [6, 12], and nicergoline [13, 14], while other studies demonstrated no clinical benefits of such nootropics [15-18]. Although nootropics alone may not significantly improve cognitive function, nootropics in combination with ChEls may enhance cholinergic neurotransmission, neurogenesis, and microperfusion in the frontal lobe, hippocampus, and striatum, ultimately delaying cognitive decline in dementia, especially in those with mild-to-moderate disease severity [19-21].

This study aimed to elucidate whether the concomitant use of nootropics with ChEls is effective in the treatment of cognitive impairment in patients with dementia. We hypothesized that dementia patients treated with both ChEls and nootropics would show less deterioration in cognitive function as assessed by mini-mental state examination (MMSE) over a 1-year follow-up period compared to dementia patients treated with ChEls only. We further hypothesized that this trend would be more evident in the neurodegenerative forms of dementia, particularly Alzheimer's dementia.

\section{Methods}

\section{Study population}

The present study aimed to observe the effectiveness of the concomitant administration of nootropics with ChEls for the treatment of cognitive deficits in patients with dementia. Data were collected and extracted via the clinical data warehouse of a university health system consisting of three general hospitals with 4,050 beds in total. Patients with any diagnosis of dementia, defined according to the International Statistical Classification of Disease and Related Health Problems 10th Revision (ICD-10) diagnostic codes F00, F01, F02, F03, F10.7, G23.1, G30, G31.0, G31.1, and G31.8, between the ages of 60 and 89 years were selected. We extracted all diagnostic codes of the patients regardless of whether they were the main or sub-diagnoses. After 
screening the entire prescription histories registered on the clinical data warehouse, which was over 7 years of record, only the patients who had their first ChEl prescription between 2012 and 2015 were included in the study. Subjects were further narrowed down to only those with mild-to-moderate dementia, as defined by their baseline MMSE total scores from 10 to $26(n=583)$ (Fig. 1). Subjects were categorized into the ChEl only group ( $n=410$ ) and the $\mathrm{ChEl}$ and nootropics combination group $(n=173)$. Subjects in the ChEl and nootropics combination group were prescribed at least one of the following nootropics during the follow-up period: choline alfoscerate, ginkgo biloba extract, acetyl-L-carnitine, nicergoline, and oxiracetam. MMSE total scores and its six-subscale scores (orientation, immediate recall, attention and calculation, delayed recall, language, and visuospatial construction) were collected at the baseline (within 30 days of the first ChEI prescription of ChEI) and at the endpoint (300-400 days after the first ChEI prescription), respectively. Baseline data on age, sex, weight, height, body mass index (BMI), blood pressure (BP), education, alcohol use, tobacco use, concomitant psychiatric medications, and comorbid diagnoses were collected during the study period. Subjects were categorized by the type of dementia according to their main diagnosis in the highest order: Alzheimer's dementia $(n=447)$, vascular dementia $(n=80)$, and other dementia $(n=56)$. For subgroup analysis, the $\mathrm{ChEl}$ and nootropics combination group of the Alzheimer's dementia patients were further classified as follows: choline alfoscerate group $(n=74)$, ginkgo biloba extract group $(n=39)$, and other nootropics group $(n=21)$.

This research protocol was exempt from an ethics review and informed consent was waived by the Institutional Review Board of Yongin Severance Hospital (9-2020-0108). This study adhered to the doctrine of the Declaration of Helsinki for Biomedical Research.

\section{Measures}

The main outcome measure was the change in cognitive function from baseline to endpoint, as assessed by the MMSE total score and its six subscale scores. Since the primary analysis did not differentiate the dementia type, subsequent analysis was conducted by comparing the changes in cognitive function between the ChEl only and ChEl and nootropics combination groups for each type of dementia separately. Further analysis was conducted in consideration of adherence to ChEl and nootropics. We defined the proportion of days covered (PDC = [Number of days in period "covered" by prescription] ${ }^{*} 100 /[$ Number of days in period] $) \geq 0.7$ to be highly adherent, based on previous studies on adherence [22]. In the subgroup analysis, MMSE score changes were analyzed among the subgroups (i.e., choline alfoscerate vs. ginkgo biloba extract vs. other nootropics) to observe the effectiveness of each nootropic type.

\section{Statistical analysis}

Baseline demographic and clinical characteristics between the two groups were compared by independent t-test for continuous variables and $\chi^{2}$ test or Fisher's exact test for categorical variables. Two-sample t-tests were utilized to compare the two treatment groups at baseline and endpoint, as well as the change from baseline to endpoint. In order to adjust for critical covariates such as time and other relevant factors, including sex, age, hypertension, diabetes mellitus, stroke, Parkinsonism, visual disturbance/hearing loss, hemiplegia/paraplegia, mood/anxiety disorder, we further used linear mixedeffect model analyses with time, treatment group, and their interaction to test the difference of the change in MMSE total score and its six-subscale scores from baseline to endpoint between the two treatment groups. The analysis of variance (ANOVA) with Bonferroni multiple comparisons test was conducted to compare the changes in MMSE total score and its six-subscale scores among the three ChEl and nootropics combination subgroup of Alzheimer's dementia (i.e., choline alfoscerate vs. ginkgo biloba extract vs. other nootropics).

All statistical analyses were conducted using IBM SPSS ver. 26 for Windows (Armonk, NY: IBM Corp.), and statistical significance was determined at $p$ $<0.05$ (two-tailed).

\section{Results}

\section{Demographic and clinical characteristics (Table 1 inserted here)}

Table 1 shows the comparison of demographic and clinical characteristics of the 583 subjects included in this study. The mean ages were similar in both groups $(75.5 \pm 6.5$ years vs. $75.5 \pm 6.6$ years in the ChEl only group and the ChEl and nootropics combination group, respectively). Females outnumbered males in both groups (266 [64.9\%] females vs. 144 [35.1\%] males in the ChEl only group; 117 [67.6\%] females vs. 56 [32.4\%] males in the $\mathrm{ChEl}$ and nootropics combination group). Regarding dementia diagnoses, Alzheimer's dementia was the most frequent in both groups (313 [76.3\%] in the ChEl only group, 134 [77.5\%] in the ChEl and nootropics combination group), and vascular dementia was the second most frequent (49 [12.0\%] in the ChEl only group, 31 [17.9\%] in the ChEl and nootropics combination group). Alcohol use was more frequent in the ChEl only group (85 [20.7\%]) than in the ChEl and nootropics combination group (23 [13.3\%]). There was no difference in the distribution of the type of ChEl prescribed between the two groups ( $p=0.446$ for donepezil, $p=0.334$ for rivastigmine, $p=0.092$ for galantamine) (Supplementary Table 1 ).

\section{Change in cognitive function: ChEl only vs. ChEl and nootropics combination group (Table 2 inserted here)}

Results for the primary outcome measure are shown in Table 2. Two-sample t-tests at baseline and endpoint showed no difference between the two groups in terms of the MMSE total score and any of its six subscale scores. A linear mixed-effects model analysis with the MMSE total score as the dependent variable also revealed no significant treatment-by-time interaction $(\mathrm{F}=1.48, \mathrm{df}=1,581, p=0.224)$. None of the six-subscale scores showed any significant treatment-by-time interaction as well, albeit the change in language subscale score showed a trend of less deterioration in the nootropics combination group than in the ChEl only group $(-0.27$ for the ChEl only group and -0.03 for the ChEl and nootropics combination group; $\mathrm{F}=$ $3.43, \mathrm{df}=1,581, p=0.065)$. 
Comparison of the change in cognitive function for each of the three types of dementia is shown in Table 3. Linear mixed-effects model analyses using the MMSE total score as the dependent variable revealed no significant treatment-by-time interaction in all three types of dementia $(F=2.10, p=0.148$ for Alzheimer's dementia, $\mathrm{F}=0.38, p=0.540$ for vascular dementia, $\mathrm{F}=0.04, p=0.906$ for other dementia). Within the subjects diagnosed with Alzheimer's dementia, the $\mathrm{ChEl}$ and nootropics combination group showed a significantly less deterioration in the MMSE language subscale score compared to the ChEl only group, revealing a significant treatment-by-time interaction ( -0.34 for the ChEl only group and 0.04 for the ChEl and nootropics combination group; $\mathrm{F}=6.86, p=0.009)$, while in the vascular dementia subjects, the ChEl and nootropics combination group showed a significantly less deterioration in the MMSE attention and calculation subscale score compared to the ChEl only group, with a significant treatment-bytime interaction ( -0.59 for the ChEl only group and 0.06 for the ChEl and nootropics combination group; $\mathrm{F}=4.44, p=0.038$ ). None of the six-subscale scores showed any significant treatment-by-time interaction in the other dementia patients. (Table 4 inserted here) For highly-adherent Alzheimer's dementia patients, the MMSE language subscale score consistently revealed a significant treatment-by-time interaction, showing favorable results for the ChEl and nootropics combination group $(-0.38$ for the ChEl only group and 0.12 for the $\mathrm{ChEl}$ and nootropics combination group; $\mathrm{F}=10.16, p=0.002)$ (Table 4). Apart from the language subscale score, a linear mixed-effects model with the MMSE visuospatial construction subscale score as the dependent variable also showed a significant treatment-by-time interaction (-0.06 for the ChEl only group and 0.06 for the ChEl and nootropics combination group; $\mathrm{F}=4.00, p=0.046)$ (Table 4).

\section{Subgroup analysis within the ChEl and nootropics combination group in Alzheimer's dementia: choline alfoscerate vs. ginkgo biloba extract vs. other nootropics}

When the three types of nootropics within the ChEl and nootropics combination group of the Alzheimer's dementia subjects were compared, choline alfoscerate and ginkgo biloba extract combination with ChEl showed significantly less declines in the MMSE total scores ( $p=0.006)$ compared to other nootropics combination (-0.28 for the choline alfoscerate group, -0.51 for the ginkgo biloba extract group, -2.81 for the other nootropics group) (Supplementary Table 2). Highly significant between-group differences, in favor of the choline alfoscerate combination and the ginkgo biloba extract combination, were shown in the MMSE language subscale score $(p=0.001)$ as well $(0.22$ for the choline alfoscerate group, 0.26 for the ginkgo biloba group, -0.95 for the other nootropics group) (Supplementary Table 2).

\section{Discussion}

Our study findings suggest that the effectiveness of nootropics combination with ChEl may be different according to the type of dementia. The difference in change in the MMSE total scores from baseline to endpoint between the ChEl only group and the ChEl and nootropics combination group was not evident, but the results implied a positive impact of ChEl augmentation with nootropics on some domains of cognitive function in certain types of dementia, particularly Alzheimer's dementia. The impact of nootropics augmentation on ChEl in Alzheimer's dementia was consistently depicted on the language domain after consideration of medical adherence and nootropics type.

Previous studies on nootropics revealed nootropics to have minimal, if any, effects on the prevention of cognitive decline. Most studies were either examined over a relatively short follow-up time or conducted with a limited number of subjects, and many of them focused on nootropic monotherapy rather than concomitant use with $\mathrm{ChEI}[6,9,10,17,23-25]$. This study aimed to compare the nootropics and ChEl combination with ChEI monotherapy in an attempt to validate the effectiveness of nootropics in association with ChEI. We examined the change in not only MMSE total scores but also in its six subscale scores over a long period of exposure (300-400 days after the first prescription), which was considered long enough to elucidate the effect of the $\mathrm{ChEl}$ and nootropics combination. We categorized the subjects by dementia types in order to clarify the impact of nootropics combination in each type of dementia separately, and mainly focused on Alzheimer's dementia, which is the most common neurodegenerative form of dementia. We did not limit nootropics to only one type of drug, but included multiple types of nootropics that are most frequently prescribed by clinicians in Korea, to speculate the effectiveness of different types of nootropics, particularly focusing on the two drugs that were most commonly used: choline alfoscerate and ginkgo biloba extract.

Choline alfoscerate is a derivative of phosphatidylcholine that enhances cholinergic transmission by upregulating acetylcholine (ACh) synthesis or release in the hippocampus [26, 27]; and thus, it ultimately facilitates learning and memory and decreases age-dependent structural changes, as seen in the frontal cortices and hippocampi of rats $[7,28]$. Previous studies reported that the combination of choline alfoscerate with ChEl significantly increased ACh concentrations and prevented volume loss in the frontal and temporal lobe, hippocampus, and striatum in both rats [29] and in Alzheimer's dementia patients [21]. One study also showed that choline alfoscerate increased hippocampal neurogenesis and provided protection against seizure-induced neuronal death and cognitive impairment [30]. A study on the supplementary effect of choline alfoscerate on speech detection and recognition among hearing aid users revealed that in the aging brain, nicotinic acetylcholine receptor activation in the medial geniculate body decreases, which contributes to deterioration in speech recognition and comprehension; and in such cases, choline precursor supplements could improve language functioning [31]. Ginkgo biloba extract, on the other hand, is hypothesized to enhance amyloid $\beta$-induced hippocampal neuron dysfunction and death, amyloid $\beta$ aggregation, and neurogenesis [32-34], and induce a significant decrease in the density of $\beta$-adrenoreceptors in the frontal cortex and hippocampus [35]. Studies have shown that the hippocampus is closely associated with language production and verbal communication, either by contributing semantic memory to spoken language, processing the mismatch between the expected sensory consequences of speaking and perceived speech feedback, or via coupling between the hippocampal/supplementary motor area and the auditory cortex, anterior 
cingulate cortex, and cerebellum [31,36]. These findings all suggest that nootropics, such as choline alfoscerate and ginkgo biloba extract, may enhance the cholinergic pathway in brain areas including the hippocampus, frontal lobes, and auditory cortex, which are critical in language processing and utilization, and enhance language function in association with ChEl administration. Language function is not only highly sensitive in detecting cognitive impairment in older age groups [37], but is also a biological marker that differentiates Alzheimer's dementia from normal aging [38]. To our knowledge, this study is the first to elucidate the effect of nootropics co-administered with ChEls on the attenuation of language domain deterioration in Alzheimer's dementia using clinical data. The possible effect of nootropics on delaying the deterioration of language function may be of great value, considering the association between cognitive decline and language function in the aging population and dementia patients.

The strength of this study lies in the methodological aspects of real-world data utilization. Many studies in Korea are actively conducted using the national claims database in an attempt to perform large-scale research [39]. However, imperative baseline characteristics of each patient, including medical histories, medications, and laboratory findings, are missing when using the national claims databases. On the other hand, the clinical data warehouse from our university healthcare system is a composition of each patient's clinical and demographic data. In this study, we were able to extract and collect critical information regarding each patient's clinical and demographic backgrounds such as, but not limited to, the education level and BMI, specific MMSE subscale scores, and detailed dementia diagnosis. As a result, we were able to make corrections for many variables that could have affected the MMSE results, including other relevant diagnoses and medical history, such as hypertension and diabetes mellitus, Parkinsonism, and visual/hearing loss. Furthermore, this study is meaningful in that until now, there have only been a few, if any, studies on the effect of nootropics on ChEl efficacy outside of the only actively researched country, Italy [19, 20,40].

The study had some limitations. Due to its retrospective nature, we were not able to control the treatment settings in terms of medication dosage, treatment duration, the overlapping periods of concomitant nootropic and ChEl use, and adherence monitoring. In order to compensate for these factors, we calculated and considered PDC, the number of days covered by the prescriptions in the total prescription periods, to reflect and consider drug adherence. Moreover, we only included subjects with MMSE scores within 300-400 days after the baseline, which might have excluded certain patients who could not take the annual MMSE test either due to a deleterious progression of dementia or because they no longer sought help or changed hospitals. In the near future, it seems that these limitations can be solved by conducting research based on a large database that combines real-world data from numerous hospitals (i.e., common data model). Finally, analyzing the six subscale domains of the MMSE may raise the issue of multiple comparison. However, through subsequent analyses, we induced consistent results at least in the Alzheimer's dementia group, of which nootropics combination could have a subtle positive impact on the language domain. Surely, further studies that more deliberately focus on the separate cognitive domains should be performed with other more qualified neuropsychological tests. Still, this study would be of best effort to observe the effectiveness of nootropics utilizing the accumulated real-world data.

\section{Conclusion}

In conclusion, our results demonstrated partial effectiveness of nootropics with ChEls on some cognitive domains in Alzheimer's dementia. The reliability of the current study was further strengthened by its 1-year follow-up period, consideration of treatment adherence, and adjustments for confounding comorbid diagnoses. This study emphasizes the need for future well-controlled studies to generalize the effect of nootropics on cognitive function across various clinical settings or cause of dementia.

\section{Abbreviations}

ChEl: Cholinesterase inhibitor; MMSE: mini-mental state examination; ICD-10: International Statistical Classification of Disease and Related Health Problems 10th Revision; BMI: body mass index; BP: blood pressure; PDC: proportion of days covered; ANOVA: analysis of variance; ACh: acetylcholine

\section{Declarations}

\section{Ethics approval and consent to participate}

This research protocol was exempt from an ethics review by the Institutional Review Board of Yongin Severance Hospital (9-2020-0108).

\section{Consent for publication}

Not applicable.

\section{Availability of data and materials}

The datasets used and/or analyzed during the current study are currently stored in the Severance Clinical Research Analysis Portal, Clinical Data Warehouse. Restrictions apply to the availability of these data, which were used per data sharing agreement for the current study, and so are not publicly available.

\section{Competing interests}

The authors declare that they have no competing interests. 


\section{Author's contributions}

WJK contributed to the conception of the study. MK and DBL collected the data and MK and SK conducted the data analysis. MK and WJK interpreted the data and drafted the manuscript. WJK, EL contributed to revising the final manuscript. All authors contributed to the development and revision of the final manuscript. All authors have read and approved the manuscript.

\section{Acknowledgements}

This study was supported by a research grant of Yongin Severance Hospital, Yonsei University College of Medicine.

\section{References}

1. World Health Organization. (2021). Dementia, 2021. Available at: https://www.who.int/news-room/fact-sheets/detail/dementia. Accessed 18 Sept 2021.

2. O'Brien JT, Holmes C, Jones M, Jones R, Livingston G, McKeith I, et al. Clinical practice with anti-dementia drugs: a revised (third) consensus statement from the British association for psychopharmacology. J Psychopharmacol 2017;31:147-168.

3. Birks J. Cholinesterase inhibitors for Alzheimer's disease. Cochrane Database Syst Rev 2006:CD005593.

4. Nicholson CD. Pharmacology of nootropics and metabolically active compounds in relation to their use in dementia. Psychopharmacology 1990;101:147-159.

5. Moreno MDJM. Cognitive improvement in mild to moderate Alzheimer's dementia after treatment with the acetylcholine precursor choline alfoscerate: a multicenter, double-blind, randomized, placebo-controlled trial. Clin Ther 2003;25:178-193.

6. Montgomery SA, Thal LJ, Amrein R. Meta-analysis of double blind randomized controlled clinical trials of acetyl-L-carnitine versus placebo in the treatment of mild cognitive impairment and mild Alzheimer's disease. Int Clin Psychopharmacol 2003;18:61-71.

7. Parnetti L, Amenta F, Gallai V. Choline alphoscerate in cognitive decline and in acute cerebrovascular disease: an analysis of published clinical data. Mech Ageing Dev 2001;122:2041-2055.

8. Parnetti L, Abate G, Bartorelli L, Cucinotta D, Cuzzupoli M, Maggioni M, et al. Multicentre study of I-alpha-glyceryl-phosphorylcholine vs ST200 among patients with probable senile dementia of Alzheimer's type. Drugs Aging 1993;3:159-164.

9. Parnetti L, Mignini F, Tomassoni D, Traini E, Amenta F. Cholinergic precursors in the treatment of cognitive impairment of vascular origin: ineffective approaches or need for re-evaluation? J Neurol Sci 2007;257:264-269.

10. DeKosky ST, Williamson JD, Fitzpatrick AL, Kronmal RA, Ives DG, Saxton JA, et al. Ginkgo biloba for prevention of dementia: a randomized controlled trial. JAMA 2008;300:2253-2262.

11. Gschwind YJ, Bridenbaugh SA, Reinhard S, Granacher U, Monsch AU, Kressig RW. Ginkgo biloba special extract LI 1370 improves dual-task walking in patients with MCl: a randomised, double-blind, placebo-controlled exploratory study. Aging Clin Exp Res 2017;29:609-619.

12. Spagnoli A, Lucca U, Menasce G, Bandera L, Cizza G, Forloni G, et al. Long-term acetyl-L-carnitine treatment in Alzheimer's disease. Neurology 1991;41:1726-1732.

13. Zang G, Fang L, Chen L, Wang C. Ameliorative effect of nicergoline on cognitive function through the PI3K/AKT signaling pathway in mouse models of Alzheimer's disease. Mol Med Rep 2018;17:7293-7300.

14. Nappi G, Bono G, Merlo P, Borromei A, Caltagirone C, Lomeo C, et al. Long-Term nicergoline treatment of mild to moderate senile dementia. Clin Drug Investig 1997;13:308-316.

15. Vellas B, Coley N, Ousset P-J, Berrut G, Dartigues J-F, Dubois B, et al. Long-term use of standardised ginkgo biloba extract for the prevention of Alzheimer's disease (GuidAge): a randomised placebo-controlled trial. Lancet Neurol 2012;11:851-859.

16. Snitz BE, O'Meara ES, Carlson MC, Arnold AM, Ives DG, Rapp SR, et al. Ginkgo biloba for preventing cognitive decline in older adults: a randomized trial. JAMA 2009;302:2663-2270.

17. Hudson S, Tabet N. Acetyl-L-carnitine for dementia. Cochrane Database Syst Rev 2003:CD003158.

18. Fioravanti M, Flicker L. Efficacy of nicergoline in dementia and other age associated forms of cognitive impairment. Cochrane Database of Syst Rev 2001:CD003159.

19. Amenta F, Carotenuto A, Fasanaro AM, Rea R, Traini E. The ASCOMALVA trial: Association between the cholinesterase inhibitor donepezil and the cholinergic precursor choline alphoscerate in Alzheimer's disease with cerebrovascular injury: interim results. J Neurol Sci 2012;322:96-101.

20. Amenta F, Tayebati SK, Vitali D, Di Tullio MA. Association with the cholinergic precursor choline alphoscerate and the cholinesterase inhibitor rivastigmine: an approach for enhancing cholinergic neurotransmission. Mech Ageing Dev 2006;127:173-179.

21. Traini E, Carotenuto A, Fasanaro AM, Amenta F. Volume analysis of brain cognitive areas in Alzheimer's disease: interim 3-year results from the ASCOMALVA trial. J Alzheimers Dis 2020;76:317-329.

22. Dao N, Lee S, Hata M, Sarino L. Impact of appointment-based medication synchronization on proportion of days covered for chronic medications. Pharmacy 2018;6:44.

23. Higgins JP, Flicker L. Lecithin for dementia and cognitive impairment. Cochrane Database Syst Rev 2003:CD001015. 
24. Birks J, Grimley Evans J. Ginkgo biloba for cognitive impairment and dementia. Cochrane Database Syst Rev 2009:CD003120.

25. Zheng Y, Xie Y, Qi M, Zhang L, Wang W, Zhang W, et al. Ginkgo biloba extract is comparable with donepezil in improving functional recovery in Alzheimer's disease: results from a multilevel characterized study based on clinical features and resting-state functional magnetic resonance imaging. Front Pharmacol 2021;12:721216.

26. Catanesi M, d'Angelo M, Antonosante A, Castelli V, Alfonsetti M, Benedetti E, et al. Neuroprotective potential of choline alfoscerate against $\beta$ amyloid injury: involvement of neurotrophic signals. Cell Biol Int 2020;44:1734-1744.

27. Sigala S, Imperato A, Rizzonelli P, Casolini P, Missale C, Spano P. L-alpha-glycerylphosphorylcholine antagonizes scopolamine-induced amnesia and enhances hippocampal cholinergic transmission in the rat. Eur J Pharmacol 1992;211:351-358.

28. Tayebati SK, Di Tullio MA, Tomassoni D, Amenta F. Neuroprotective effect of treatment with galantamine and choline alphoscerate on brain microanatomy in spontaneously hypertensive rats. J Neurol Sci 2009;283:187-194.

29. Amenta F, Tayebati SK, Vitali D, Di Tullio MA. Association with the cholinergic precursor choline alphoscerate and the cholinesterase inhibitor rivastigmine: an approach for enhancing cholinergic neurotransmission. Mech Ageing Dev 2006;127:173-179.

30. Lee SH, Choi BY, Kim JH, Kho AR, Sohn M, Song HK, et al. Late treatment with choline alfoscerate (I-alpha glycerylphosphorylcholine, a-GPC) increases hippocampal neurogenesis and provides protection against seizure-induced neuronal death and cognitive impairment. Brain Res 2017;1654:66-76.

31. Na G, Kwak SH, Jang SH, Noh HE, Kim J, Yang S, et al. Supplementary effect of choline alfoscerate on speech recognition in patients with agerelated hearing loss: a prospective study in 34 patients (57 ears). Front Aging Neurosci 2021;13:684519.

32. Bastianetto S, Ramassamy C, Doré S, Christen Y, Poirier J, Quirion R. The ginkgo biloba extract (EGb 761) protects hippocampal neurons against cell death induced by beta-amyloid. Eur J Neurosci 2000;12:1882-1890.

33. Luo Y, Smith JV, Paramasivam V, Burdick A, Curry KJ, Buford JP, et al. Inhibition of amyloid- $\beta$ aggregation and caspase-3 activation by the ginkgo biloba extract EGb761. Proc Natl Acad Sci 2002;99:12197-12202.

34. Tchantchou F, Xu Y, Wu Y, Christen Y, Luo Y. EGb 761 enhances adult hippocampal neurogenesis and phosphorylation of CREB in transgenic mouse model of Alzheimer's disease. FASEB J 2007;21:2400-2408.

35. Hadjiivanova Cl, Petkov VV. Effect of Ginkgo biloba extract on $\beta$-adrenergic receptors in different rat brain regions. Phytother Res 2002;16:488-490.

36. van de Ven V, Waldorp L, Christoffels I. Hippocampus plays a role in speech feedback processing. Neuroimage 2020;223:117319.

37. Alegret M, Peretó M, Pérez A, Valero S, Espinosa A, Ortega G, et al. The role of verb fluency in the detection of early cognitive impairment in Alzheimer's disease. J Alzheimers Dis 2018;62:611-619.

38. Salmon DP, Bondi MW. Neuropsychological assessment of dementia. Annu Rev Psychol 2009;60:257-282.

39. Ryu D-R. Introduction to the medical research using national health insurance claims database. Ewha Med J 2017;40:66-70.

40. Colucci L, Bosco M, Rosario Ziello A, Rea R, Amenta F, Fasanaro AM. Effectiveness of nootropic drugs with cholinergic activity in treatment of cognitive deficit: a review. J Exp Pharmacol 2012;4:163-172.

\section{Tables}

Table 1. Demographic and clinical characteristics of the cholinesterase inhibitor only group and the nootropics combination group 


\begin{tabular}{|c|c|c|c|}
\hline Variable & $\begin{array}{l}\text { ChEl only } \\
(n=410)\end{array}$ & $\begin{array}{l}\text { ChEl + nootropics } \\
(n=173)\end{array}$ & $p$ value \\
\hline Age (years) & $75.5 \pm 6.5$ & $75.5 \pm 6.6$ & 0.880 \\
\hline Weight $(\mathrm{kg})^{\mathrm{a}}$ & $56.4 \pm 9.8$ & $56.7 \pm 12.2$ & 0.843 \\
\hline Height $(\mathrm{cm})^{\mathrm{b}}$ & $157.3 \pm 10.1$ & $156.1 \pm 11.5$ & 0.274 \\
\hline BMI $\left(\mathrm{kg} / \mathrm{m}^{2}\right)^{\mathrm{c}}$ & $22.8 \pm 3.8$ & $23.3 \pm 3.8$ & 0.265 \\
\hline \multicolumn{4}{|l|}{ Blood pressure $(\mathrm{mmHg})^{d}$} \\
\hline Systolic & $130.3 \pm 20.8$ & $129.1 \pm 22.1$ & 0.576 \\
\hline Diastolic & $75.6 \pm 12.9$ & $75.6 \pm 12.9$ & 0.962 \\
\hline \multicolumn{4}{|l|}{ Sex } \\
\hline Male & $144(35.1)$ & $56(32.4)$ & 0.523 \\
\hline Female & $266(64.9)$ & $117(67.6)$ & \\
\hline \multicolumn{4}{|l|}{ Education (years) ${ }^{\mathrm{e}}$} \\
\hline No education & $55(13.4)$ & $20(11.6)$ & 0.651 \\
\hline Elementary school & $94(22.9)$ & $43(24.9)$ & \\
\hline Middle/high school & $90(21.9)$ & $31(7.9)$ & \\
\hline Bachelor's/master's degree & $64(15.6)$ & $30(17.3)$ & \\
\hline \multicolumn{4}{|l|}{ Alcohol use ${ }^{f}$} \\
\hline Yes & $85(20.7)$ & $23(13.3)$ & 0.011 \\
\hline No & $203(49.5)$ & $107(61.8)$ & \\
\hline \multicolumn{4}{|l|}{ Tobacco use ${ }^{g}$} \\
\hline Yes & $23(5.6)$ & $7(4.0)$ & 0.245 \\
\hline No & $224(54.6)$ & $114(65.9)$ & \\
\hline \multicolumn{4}{|l|}{ Psychiatric medication } \\
\hline Antipsychotics & $73(17.8)$ & $34(19.7)$ & 0.598 \\
\hline Benzodiazepines, hypnotics & $119(29.0)$ & $45(26.0)$ & 0.460 \\
\hline Anticholinergics & $83(20.2)$ & $43(24.9)$ & 0.217 \\
\hline \multicolumn{4}{|l|}{ Dementia diagnoses } \\
\hline Alzheimer's dementia & $313(76.3)$ & $134(77.5)$ & 0.771 \\
\hline Vascular dementia & $49(12.0)$ & $31(17.9)$ & 0.056 \\
\hline Unspecified dementia & $17(4.1)$ & $6(3.5)$ & 0.701 \\
\hline Frontotemporal dementia & $8(2.0)$ & $0(0)$ & 0.113 \\
\hline Progressive supranuclear palsy & $16(3.9)$ & $0(0)$ & 0.004 \\
\hline Alcohol induced persisting dementia & $1(0.2)$ & $0(0)$ & 1.000 \\
\hline Other specified degenerative disease of nervous system & $6(1.5)$ & $2(1.2)$ & 1.000 \\
\hline \multicolumn{4}{|l|}{ Comorbid diagnoses } \\
\hline Diabetes mellitus & $81(19.8)$ & $50(28.9)$ & 0.016 \\
\hline Hypertension & $138(33.7)$ & $70(40.5)$ & 0.117 \\
\hline Hyperlipidemia & $55(13.4)$ & $29(16.8)$ & 0.293 \\
\hline Stroke ${ }^{h}$ & $36(8.8)$ & $36(20.8)$ & $<0.001$ \\
\hline Parkinsonism & 69 (16.8) & $12(6.9)$ & 0.002 \\
\hline
\end{tabular}




\begin{tabular}{|llll|}
\hline Visual disturbance/hearing loss & $26(6.3)$ & $20(11.6)$ & 0.033 \\
\hline Hemiplegia/paraplegia & $3(0.7)$ & $6(3.5)$ & 0.023 \\
Asthma/COPD & $18(4.4)$ & $11(6.4)$ & 0.318 \\
\hline Renal insufficiency & $25(6.1)$ & $14(8.1)$ & 0.378 \\
Mood/anxiety disorder & $141(34.4)$ & $75(43.4)$ & 0.041 \\
Other psychiatric disorder & $26(6.3)$ & $12(6.9)$ & 0.790 \\
Any malignancy & $26(6.3)$ & $10(5.8)$ & 0.797 \\
\hline
\end{tabular}

Values are presented as mean \pm standard deviation or number (\%). Independent t-test was used for continuous variables, and $\chi^{2}$ test or Fisher's exact test was used for categorical variables.

ChEl, cholinesterase inhibitor; BMI, body mass index; COPD, chronic obstructive pulmonary disease

${ }^{\mathrm{a}}$ Missing: ChEl only $=132, \mathrm{ChEI}+$ nootropics $=51$

${ }^{\mathrm{b}}$ Missing: ChEl only $=136, \mathrm{ChEl}+$ nootropics $=53$

${ }^{\mathrm{C}}$ Missing: $\mathrm{ChEl}$ only $=81, \mathrm{ChEl}+$ nootropics $=33$

${ }^{\mathrm{d}}$ Missing: ChEl only $=102, \mathrm{ChEl}+$ nootropics $=40$

e Missing: ChEl only $=107, \mathrm{ChEI}+$ nootropics $=49$

fMissing: ChEl only $=122$, ChEl + nootropics $=43$

gMissing: ChEl only $=163, \mathrm{ChEl}+$ nootropics $=52$

${ }^{\mathrm{h}}$ Cerebral hemorrhage and ischemic stroke

iPsychotic disorder and substance use disorder

Table 2. Results of significance testing and mixed model analyses for mini mental state examination (MMSE): Cholinesterase Inhibitor Only vs. Cholinesterase Inhibitor and Nootropics Combination ${ }^{\mathrm{a}}$ 


\begin{tabular}{|c|c|c|c|c|c|c|c|c|c|c|c|c|}
\hline \multirow[b]{2}{*}{ MMSE } & \multicolumn{3}{|c|}{ Baseline } & \multicolumn{3}{|c|}{ Endpoint } & \multicolumn{3}{|c|}{ Difference in scores } & \multicolumn{3}{|c|}{ Group-time interaction ${ }^{b}$} \\
\hline & $\begin{array}{l}\text { ChEl } \\
\text { only }\end{array}$ & $\begin{array}{l}\text { ChEl + } \\
\text { nootropics }\end{array}$ & $\begin{array}{l}p \\
\text { value }^{c}\end{array}$ & $\begin{array}{l}\text { ChEl } \\
\text { only }\end{array}$ & $\begin{array}{l}\text { ChEl + } \\
\text { nootropics }\end{array}$ & $p$ value $^{c}$ & $\begin{array}{l}\text { ChEI } \\
\text { only }\end{array}$ & $\begin{array}{l}\text { ChEl + } \\
\text { nootropics }\end{array}$ & $p$ value $^{c}$ & $\mathbf{F}$ & $\begin{array}{l}\text { Degrees } \\
\text { of } \\
\text { freedom }\end{array}$ & $p$ value $^{\mathrm{e}}$ \\
\hline \multirow[t]{2}{*}{ Total } & 20.00 & 20.27 & 0.487 & 18.87 & 19.56 & 0.152 & -1.13 & -0.71 & 0.199 & 1.48 & 1,581 & 0.224 \\
\hline & \pm 4.30 & \pm 4.26 & & \pm 5.43 & \pm 5.13 & & \pm 3.98 & \pm 3.47 & & & & \\
\hline \multirow[t]{2}{*}{ Orientation } & 6.81 & 6.94 & 0.533 & 6.28 & 6.54 & 0.276 & -0.53 & -0.40 & 0.504 & 0.45 & 1,581 & 0.504 \\
\hline & \pm 2.33 & \pm 2.23 & & \pm 2.70 & \pm 2.57 & & \pm 2.21 & \pm 2.15 & & & & \\
\hline \multirow{2}{*}{$\begin{array}{l}\text { Immediate } \\
\text { recall }\end{array}$} & 2.83 & 2.84 & 0.925 & 2.74 & 2.77 & 0.526 & -0.10 & -0.06 & 0.594 & 0.28 & 1,581 & 0.594 \\
\hline & \pm 0.47 & \pm 0.47 & & \pm 0.63 & \pm 0.59 & & \pm 0.66 & \pm 0.63 & & & & \\
\hline \multirow{2}{*}{$\begin{array}{l}\text { Attention \& } \\
\text { calculation }\end{array}$} & 1.99 & 2.01 & 0.881 & 1.81 & 1.95 & 0.327 & -0.18 & -0.06 & 0.364 & 0.83 & 1,581 & 0.364 \\
\hline & \pm 1.58 & \pm 1.57 & & \pm 1.58 & \pm 1.62 & & \pm 1.53 & \pm 1.29 & & & & \\
\hline \multirow{2}{*}{$\begin{array}{l}\text { Delayed } \\
\text { recall }\end{array}$} & 0.92 & 1.10 & 0.064 & 0.90 & 0.93 & 0.715 & -0.03 & -0.17 & 0.150 & 2.29 & 1,581 & 0.131 \\
\hline & \pm 1.00 & \pm 1.11 & & \pm 1.06 & \pm 1.10 & & \pm 1.02 & \pm 1.16 & & & & \\
\hline \multirow[t]{2}{*}{ Language } & 6.97 & 6.87 & 0.387 & 6.70 & 6.84 & 0.295 & -0.27 & -0.03 & 0.065 & 3.43 & 1,581 & 0.065 \\
\hline & \pm 1.22 & \pm 1.41 & & \pm 1.46 & \pm 1.55 & & \pm 1.45 & \pm 1.43 & & & & \\
\hline Visuospatial & 0.47 & 0.50 & 0.561 & 0.44 & 0.51 & 0.111 & -0.03 & 0.01 & 0.375 & 0.79 & 1,581 & 0.375 \\
\hline construction & \pm 0.50 & \pm 0.50 & & \pm 0.50 & \pm 0.50 & & \pm 0.56 & \pm 0.58 & & & & \\
\hline
\end{tabular}

Values are presented as mean \pm standard deviation.

MMSE, mini-mental state examination; ChEl, cholinesterase inhibitor

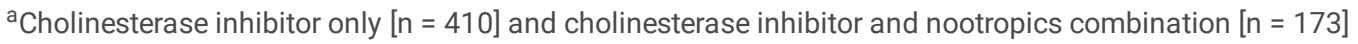

${ }^{\mathrm{b}}$ The results for the linear mixed-effects model were adjusted for covariates of sex, age, hypertension, diabetes mellitus, stroke, Parkinsonism, visual disturbance/hearing loss, hemiplegia/paraplegia, and mood/anxiety disorder.

${ }^{\mathrm{c}} p$ value for t-test

${ }^{d} p$ value for linear mixed-effects model

Table 3. Results of mixed model analyses ${ }^{a}$ for mini-mental state examination (MMSE) among the three dementia subgroups 


\begin{tabular}{|c|c|c|c|c|c|c|c|c|c|c|c|c|}
\hline & \multicolumn{4}{|c|}{$\begin{array}{l}\text { Alzheimer's dementia } \\
(n=447)\end{array}$} & \multicolumn{4}{|c|}{$\begin{array}{l}\text { Vascular dementia } \\
(n=80)\end{array}$} & \multicolumn{4}{|c|}{$\begin{array}{l}\text { Others } \\
(n=56)\end{array}$} \\
\hline & \multicolumn{2}{|c|}{ Difference in scores } & \multicolumn{2}{|c|}{$\begin{array}{l}\text { Group-time } \\
\text { interaction }\end{array}$} & \multicolumn{2}{|c|}{ Difference in scores } & \multicolumn{2}{|c|}{$\begin{array}{l}\text { Group-time } \\
\text { interaction }\end{array}$} & \multicolumn{2}{|c|}{ Difference in scores } & \multicolumn{2}{|c|}{$\begin{array}{l}\text { Group-time } \\
\text { interaction }\end{array}$} \\
\hline MMSE & $\begin{array}{l}\text { ChEI } \\
\text { only } \\
(n= \\
313)\end{array}$ & $\begin{array}{l}\text { ChEl + } \\
\text { nootropics (n } \\
=134)\end{array}$ & $\mathbf{F}$ & $p$ value & $\begin{array}{l}\text { ChEl } \\
\text { only } \\
(n= \\
49)\end{array}$ & $\begin{array}{l}\text { ChEl + } \\
\text { nootropics (n } \\
=31 \text { ) }\end{array}$ & $F$ & $p$ value & $\begin{array}{l}\text { ChEl } \\
\text { only } \\
(n= \\
48)\end{array}$ & $\begin{array}{l}\text { ChEl + } \\
\text { nootropics } \\
(n=8)\end{array}$ & $\mathbf{F}$ & $p$ value \\
\hline \multirow[t]{2}{*}{ Total } & -1.30 & -0.75 & 2.10 & 0.148 & -0.88 & -0.35 & 0.38 & 0.540 & -0.27 & -1.38 & 0.04 & 0.906 \\
\hline & \pm 3.87 & \pm 3.27 & & & $\stackrel{ \pm}{3.46}$ & \pm 4.06 & & & $\stackrel{ \pm}{5.04}$ & \pm 4.66 & & \\
\hline \multirow[t]{2}{*}{ Orientation } & -0.62 & -0.45 & 0.66 & 0.417 & -0.33 & -0.16 & 0.09 & 0.771 & -0.15 & -0.50 & 0.14 & 0.707 \\
\hline & \pm 2.16 & \pm 1.91 & & & $\stackrel{ \pm}{2.04}$ & \pm 3.03 & & & $\stackrel{ \pm}{2.67}$ & \pm 1.93 & & \\
\hline \multirow{2}{*}{$\begin{array}{l}\text { Immediate } \\
\text { recall }\end{array}$} & -0.08 & -0.09 & 0.01 & 0.922 & -0.12 & 0.10 & 1.55 & 0.217 & -0.15 & -0.25 & 0.01 & 0.937 \\
\hline & \pm 0.65 & \pm 0.62 & & & $\stackrel{ \pm}{0.81}$ & \pm 0.70 & & & $\stackrel{ \pm}{0.62}$ & \pm 0.46 & & \\
\hline \multirow{2}{*}{$\begin{array}{l}\text { Attention \& } \\
\text { calculation }\end{array}$} & -0.18 & -0.11 & 0.21 & 0.651 & -0.59 & 0.06 & 4.44 & 0.038 & 0.25 & 0.38 & 1.13 & 0.293 \\
\hline & \pm 1.50 & \pm 1.28 & & & \pm & \pm 1.32 & & & \pm & \pm 1.41 & & \\
\hline \multirow{2}{*}{$\begin{array}{l}\text { Delayed } \\
\text { recall }\end{array}$} & -0.02 & -0.19 & 2.46 & 0.117 & 0.00 & -0.13 & 0.30 & 0.584 & -0.10 & 0.00 & 1.35 & 0.252 \\
\hline & \pm 1.05 & \pm 1.15 & & & \pm .94 & \pm 1.15 & & & \pm .99 & \pm 1.51 & & \\
\hline \multirow[t]{2}{*}{ Language } & -0.34 & 0.04 & 6.86 & 0.009 & 0.14 & -0.10 & 0.96 & 0.331 & -0.23 & -1.00 & 1.90 & 0.175 \\
\hline & \pm 1.45 & \pm 1.39 & & & $\pm \frac{ \pm}{1.04}$ & \pm 1.11 & & & $\stackrel{ \pm}{1.72}$ & \pm 2.67 & & \\
\hline Visuospatial & -0.05 & 0.05 & 3.28 & 0.071 & -0.04 & -0.16 & 0.97 & 0.327 & 0.56 & 0.76 & 0.18 & 0.677 \\
\hline construction & \pm 0.57 & \pm 0.58 & & & $\stackrel{ \pm}{0.54}$ & \pm 0.53 & & & $\stackrel{ \pm}{0.08}$ & \pm 0.27 & & \\
\hline
\end{tabular}

Values are presented as mean \pm standard deviation.

MMSE, mini-mental state examination; ChEl, cholinesterase inhibitor

${ }^{a}$ The results for the linear mixed-effects model were adjusted for covariates of sex, age, hypertension, diabetes mellitus, stroke, Parkinsonism, visual disturbance/hearing loss, hemiplegia/paraplegia, and mood/anxiety disorder.

Table 4. Results of mixed model analyses ${ }^{\mathrm{a}}$ for mini-mental state examination (MMSE) for highly-adherent ${ }^{\mathrm{b}}$ Alzheimer's Dementia Patients 


\begin{tabular}{|c|c|c|c|c|c|c|c|c|c|c|c|c|}
\hline & \multicolumn{4}{|c|}{$\begin{array}{l}\text { Alzheimer's dementia } \\
(n=412)\end{array}$} & \multicolumn{4}{|c|}{$\begin{array}{l}\text { Vascular dementia } \\
(n=72)\end{array}$} & \multicolumn{4}{|c|}{$\begin{array}{l}\text { Others } \\
(n=53)\end{array}$} \\
\hline & \multicolumn{2}{|c|}{ Difference in scores } & \multicolumn{2}{|c|}{$\begin{array}{l}\text { Group-time } \\
\text { interaction }\end{array}$} & \multicolumn{2}{|c|}{ Difference in scores } & \multicolumn{2}{|c|}{$\begin{array}{l}\text { Group-time } \\
\text { interaction }\end{array}$} & \multicolumn{2}{|c|}{ Difference in scores } & \multicolumn{2}{|c|}{$\begin{array}{l}\text { Group-time } \\
\text { interaction }\end{array}$} \\
\hline MMSE & $\begin{array}{l}\text { ChEl } \\
\text { only } \\
(n= \\
300)\end{array}$ & $\begin{array}{l}\text { ChEl + } \\
\text { nootropics (n } \\
=112 \text { ) }\end{array}$ & $\mathbf{F}$ & $p$ value & $\begin{array}{l}\text { ChEl } \\
\text { only } \\
(n= \\
45)\end{array}$ & $\begin{array}{l}\text { ChEl + } \\
\text { nootropics (n } \\
=27 \text { ) }\end{array}$ & $\mathbf{F}$ & $p$ value & $\begin{array}{l}\text { ChEl } \\
\text { only } \\
(n= \\
45)\end{array}$ & $\begin{array}{l}\text { ChEl + } \\
\text { nootropics } \\
(n=8)\end{array}$ & $\mathbf{F}$ & $p$ value \\
\hline \multirow[t]{2}{*}{ Total } & -1.36 & -0.77 & 2.18 & 0.141 & -0.78 & -0.59 & 0.04 & 0.841 & -0.36 & -1.38 & 0.27 & 0.606 \\
\hline & $\frac{ \pm}{3.87}$ & \pm 2.85 & & & $\frac{ \pm}{3.51}$ & \pm 4.17 & & & $\frac{ \pm}{5.19}$ & \pm 4.66 & & \\
\hline \multirow[t]{2}{*}{ Orientation } & -0.64 & -0.54 & 0.22 & 0.640 & -0.38 & -0.22 & 0.07 & 0.795 & -0.18 & -0.50 & 0.10 & 0.753 \\
\hline & $\stackrel{ \pm}{2.16}$ & \pm 1.82 & & & $\stackrel{ \pm}{1.84}$ & \pm 3.23 & & & $\stackrel{ \pm}{2.76}$ & \pm 1.93 & & \\
\hline \multirow{2}{*}{$\begin{array}{l}\text { Immediate } \\
\text { recall }\end{array}$} & -0.08 & -0.07 & 0.03 & 0.865 & -0.13 & 0.11 & 1.54 & 0.219 & -0.16 & -0.25 & 0.16 & 0.692 \\
\hline & $\stackrel{ \pm}{0.66}$ & \pm 0.57 & & & $\stackrel{ \pm}{0.84}$ & \pm 0.75 & & & $\stackrel{ \pm}{0.64}$ & \pm 0.46 & & \\
\hline \multirow{2}{*}{$\begin{array}{l}\text { Attention \& } \\
\text { calculation }\end{array}$} & -0.18 & -0.12 & 0.16 & 0.689 & -0.58 & 0.04 & 0.04 & 0.841 & 0.13 & 0.38 & 0.14 & 0.714 \\
\hline & $\frac{ \pm}{1.49}$ & \pm 1.32 & & & $\frac{ \pm}{1.42}$ & \pm 1.22 & & & \pm & \pm 1.41 & & \\
\hline \multirow{2}{*}{$\begin{array}{l}\text { Delayed } \\
\text { recall }\end{array}$} & -0.01 & -0.22 & 3.35 & 0.068 & 0.07 & -0.19 & 1.06 & 0.307 & -0.07 & 0.00 & 0.03 & 0.872 \\
\hline & $\stackrel{ \pm}{1.03}$ & \pm 1.11 & & & $\stackrel{ \pm}{0.92}$ & \pm 1.15 & & & $\stackrel{ \pm}{0.99}$ & \pm 1.51 & & \\
\hline \multirow[t]{2}{*}{ Language } & -0.38 & 0.12 & 10.16 & 0.002 & 0.20 & -0.14 & 2.21 & 0.142 & -0.22 & -1.00 & 1.14 & 0.291 \\
\hline & $\stackrel{ \pm}{1.46}$ & \pm 1.26 & & & $\stackrel{ \pm}{1.04}$ & \pm 1.11 & & & $\frac{ \pm}{1.74}$ & \pm 2.67 & & \\
\hline Visuospatial & -0.06 & 0.06 & 4.00 & 0.046 & -0.02 & -0.15 & 0.92 & 0.341 & 0.13 & 0.00 & 0.36 & 0.552 \\
\hline construction & $\stackrel{ \pm}{0.56}$ & \pm 0.59 & & & $\stackrel{ \pm}{0.54}$ & \pm 0.53 & & & $\stackrel{ \pm}{0.55}$ & \pm 0.76 & & \\
\hline
\end{tabular}

Values are presented as mean \pm standard deviation.

MMSE, mini-mental state examination; ChEl, cholinesterase inhibitor

aThe results for the linear mixed-effects model were adjusted for covariates of sex, age, hypertension, diabetes mellitus, stroke, Parkinsonism, visual disturbance/hearing loss, hemiplegia/paraplegia, and mood/anxiety disorder.

bHighly-adherent subjects are defined as proportion of days covered $\geq 0.7$; Proportion of days covered $=$ (Number of days in the period "covered" by prescription)* $100 /$ (Number of days in period)

\section{Figures}




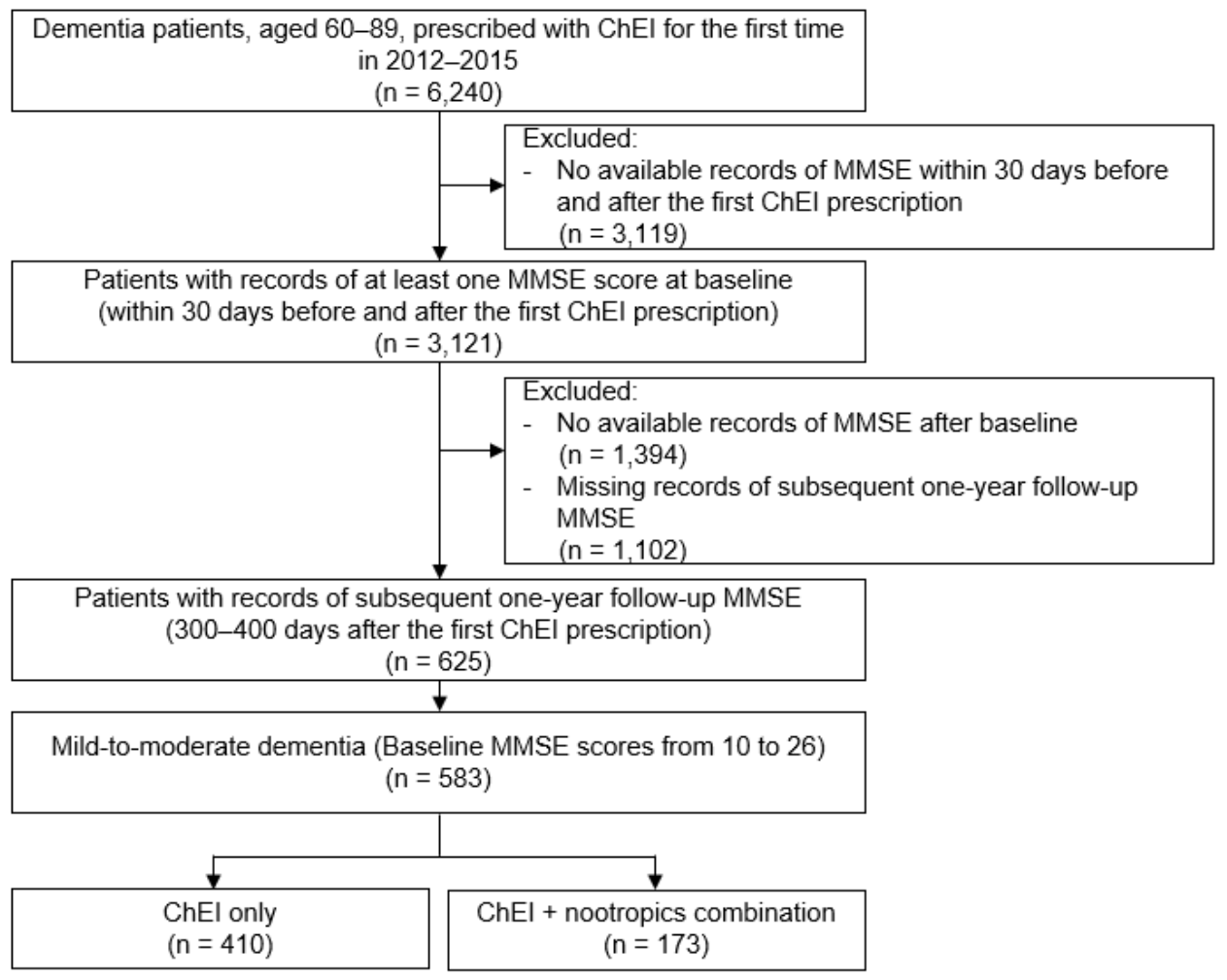

Figure 1

Flow diagram of study sample selection.

ChEl, cholinesterase inhibitor; MMSE, mini-mental state examination

\section{Supplementary Files}

This is a list of supplementary files associated with this preprint. Click to download.

- SupplementaryTable1.docx

- SupplementaryTable2.docx 